\title{
A evolução da poesia visual: da Grécia Antiga aos infopoemas
}

Henrique Piccinato Xavier Universidade de São Paulo/ECA-USP - bolsista $/ C$ 


\section{Resumo}

Este estudo visa a mostrar conceitualmente o que é a poesia visual e demonstrar sua evolução pelo tempo, desde seu surgimento na antiga Alexandria até os mais recentes poemas visuais realizados no computador.

\section{Palavras-chave}

rede intersemiótica, poesia visual, poema performance, infopoema

\section{Abstract}

This study aims to explain conceptually what is visual poetry. It also shows the evolution of visual poetry through time, since its appearance in ancient Alexandria to late visual poems done in the computer.

\section{Key words}

intersemiotic net, visual poetry, performance poem, infopoem 


\section{poesia visual ou figurativa consiste em uma forma de arte 1 que procura a união de dois códigos distintos - o verbal e o}

rede intersemiótica. A ativação dessa rede se dá quando os mecanismos lingüísticos de decodificação são colocados em sincronia com aqueles que governam a recepção das imagens. A coexistência da palavra e imagem é feita através da direta transformação de símbolos verbais em elementos visualmente expressivos.

A escrita tradicional consiste na tradução simbólica de nossa oralidade em caracteres visuais, as letras. Essa escrita, embora visual, abandona suas características plásticas, buscando essencialmente representar a oralidade. Segundo E. M. de Melo e Castro (1993), no quadrante oral, o signo interpretante é especificamente diacrônico, extensivo, analítico, temporal, abstrato. Nela a poesia se prende então em valores musicais (sonoros, temporais e rítmicos) por meio de rimas, assonâncias, aliterações etc.

A poesia visual busca trabalhar as características plásticas da escrita ressaltando os valores visuais, espaciais, considerando-a como uma mancha gráfica, um desenho, uma relação de figura-fundo na folha, como a admiração de um arabesco cujo significado da grafia desconhecemos. Segundo E. M. de Melo e Castro (1993), no quadrante visual, o signo interpretante é especificamente sincrônico, compacto, sintético, espacial, concreto. A poesia não só como símbolos representativos de uma sonoridade anterior à própria escrita, mas sim como uma escrita tácita que em si já é forma carregada de sentido. A página que não é mais um depósito frio de letras, mas um suporte espacial ativo, como a tela de uma pintura.

A poesia visual sinteticamente: uma rede intersemiótica da palavra verbal somada a palavra imagem, formulações 
"verbivocovisuais" na definição do grupo Noigrandes de São Paulo, composições não somente para serem lidas mas também olhadas.

A poesia visual aparece em fases de profundas transições históricas, na fronteira entre épocas, quando intensas alterações econômicas, técnicas e sociais estão ocorrendo. Nessas fases de complexa e complicada organização, a estrutura linguiístico-semântica se encontra desgastada e saturada, incapaz de acompanhar o turbilhão das mudanças. Neste momento, surge a poesia visual como uma ferramenta nas mãos do artista que se debruça sobre linguagem em uma tentativa de renová-la e reestruturá-la eticamente. Nas palavras do norte-americano Geoffery Cook (em Uma Rede Intersemiótica, 1993, CASTRO, E. M. de Melo e.), um sinal de transformação, um grito do poeta, já que o conteúdo do passado está canceroso e uma nova pele deve ser produzida para conter os sonhos do futuro uma afirmação de que nada significativo pode já ser dito antes de reestruturarmos a concepção básica do que é uma cultura histórica.

Segundo E. M. de Melo e Castro (1993), a poesia visual aparece de uma forma consistente quatro vezes na história da arte ocidental: durante o período alexandrino, na renascença carolíngea, no período barroco e no século XX. Pode observarse ainda que cada um desses surtos de poesia visual se relaciona com o fim de um período histórico e começo de uma nova época.

Datando de 300 anos antes de Cristo e realizadas na Alexandria, as tecnofanias de Símias de Rodes constituem os primeiros poemas visuais conhecidos. São elas: "O Machado", "As Asas" e "O Ovo".

Alexandria, a imponente capital da cultura helênica - a qual unia a cultura grega às culturas orientais, principalmente egípcia e persa - conhecida por suas fabulosas obras como o Colosso de Rodes, a escultura de Laocoonte, o seu gigantesco farol e sua riquíssima e famosa biblioteca.

Deste período altamente intelectualizado, que mesclava o espírito especulativo grego com as ciências orientais, destacaram-se diversos avanços científicos como os de Euclides, na geometria, e de 
Arquimedes, na física. O heliocentrismo de Aristarco de Samos e o geocentrimo de Ptolomeu, também são conhecidos os mitos da criação do primeiro robô ou autômato.

A convivência da abstrata literatura grega com as escrituras egípcias, árabes e pérsicas, de forte cunho visual, é encarada como a condição preliminar para o surgimento dos primeiros poemas visuais.
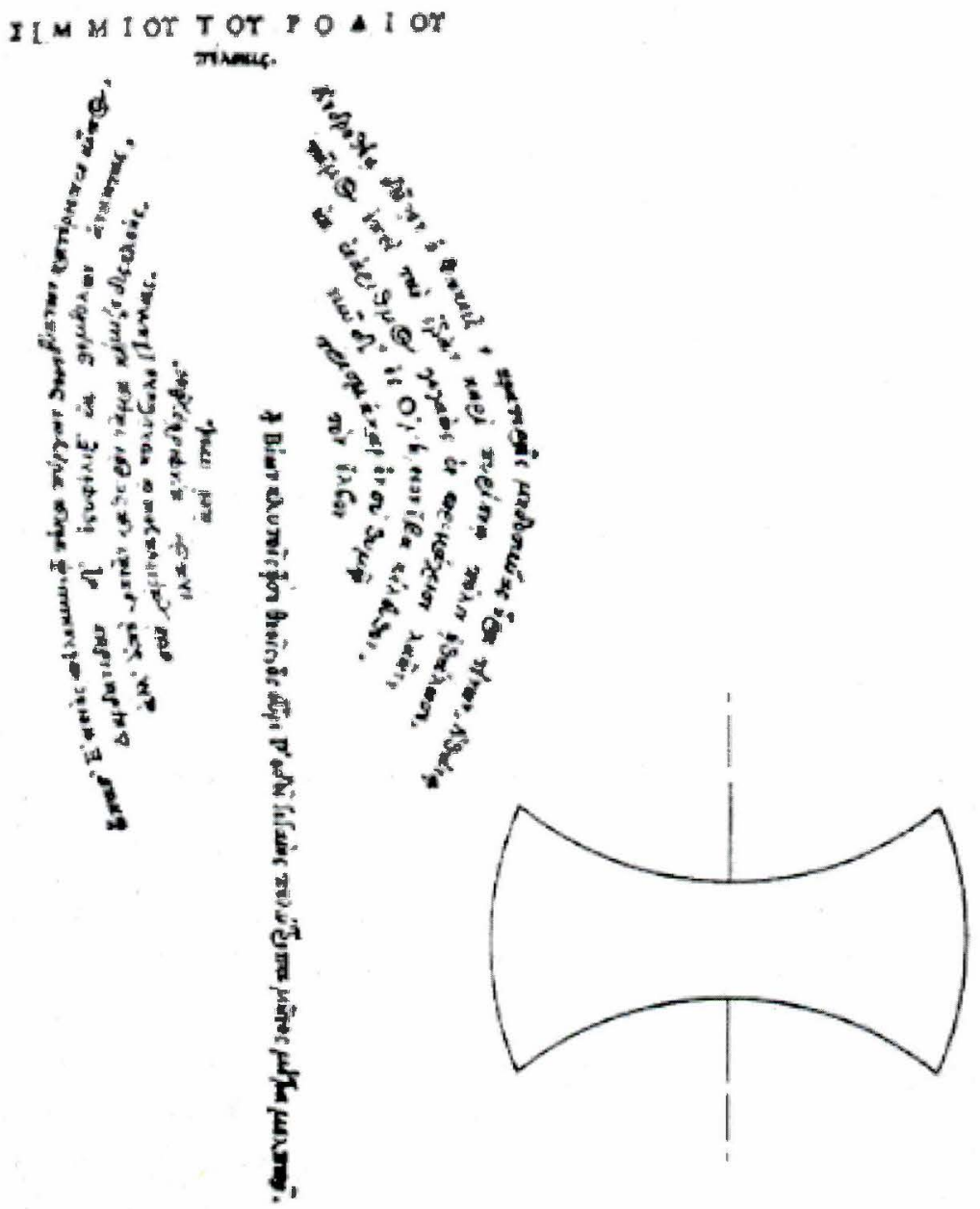

"O Machado", Simias de Rodes. 
As tecnofanias de Símias de Rodes não são apenas poemas visuais, mas também labirintos de leitura, sendo necessário conhecer a estrutura peculiar da distribuição das frases para o desvendamento do texto. Como na leitura do poema "O Ovo", não se trata de um

\section{$Y I M I$ Or $T$ OT POAIOr nIETIIO N.}

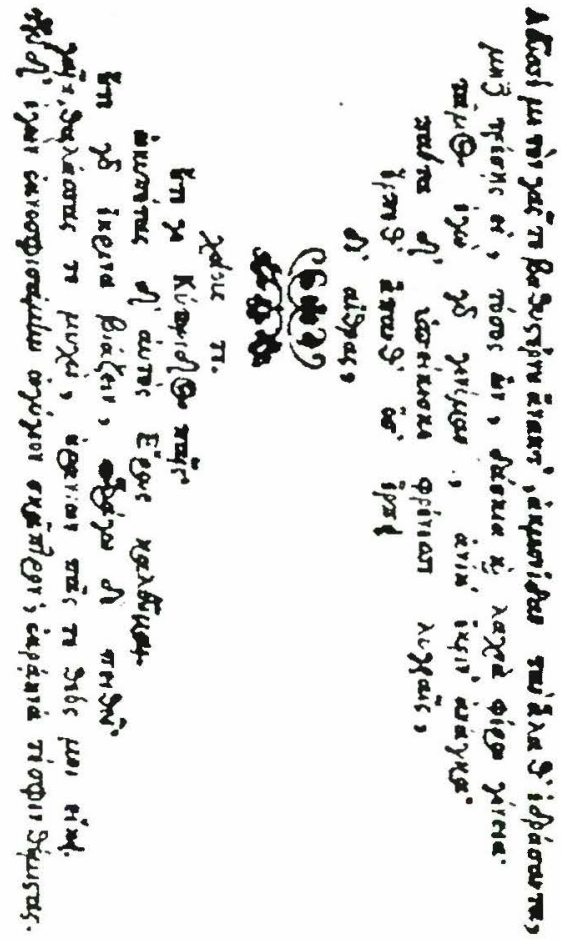

"As Asas", 325a.C., Simias de Rodes. 
simples poema de forma oval, mas de um ovo que se constrói das extremidades para o centro, através de uma leitura saltada de seu primeiro verso para o último, do segundo verso para o penúltimo, do terceiro para o antepenúltimo assim sucessivamente por seus vinte versos.

Os poemas tratam de temas clássicos da literatura grega. "O Machado" tem como tema uma inscrição sobre o machado da deusa Minerva por Epeio, o criador do Cavalo de Tróia. "O Ovo",

\section{IMMIOT TOr POSIOr \\ $\Omega \circ N_{0}$}

\section{Kaninat}

paripos nitip

dior nor ogcen.

sured dig. di arrá

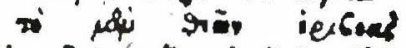

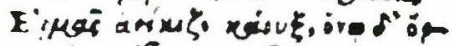

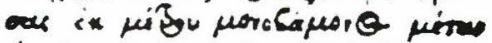

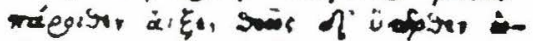

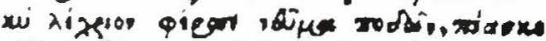

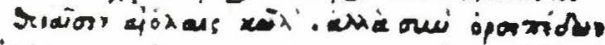

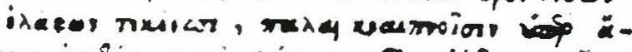

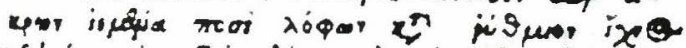

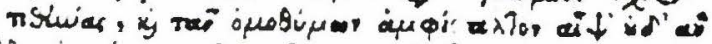

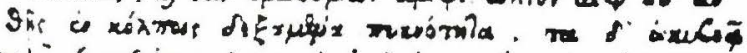

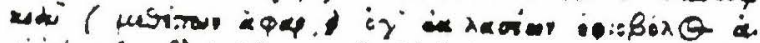

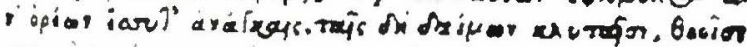

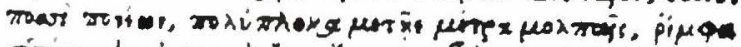

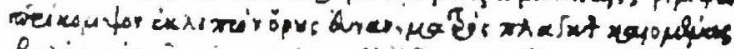

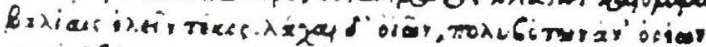

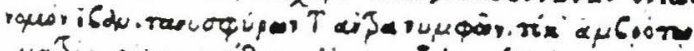

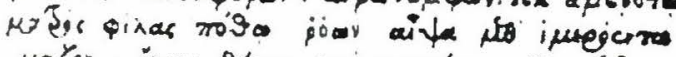

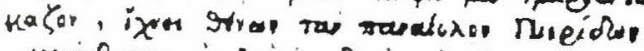

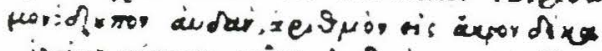
ixistrocuer rifu is

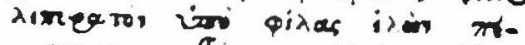

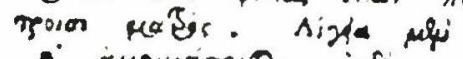

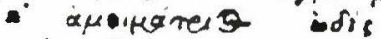
i) pial of a $\operatorname{xes}$. 


\title{
OOvo
}

\author{
Acolhe \\ da fêmea canora \\ este novo urdume que, animosa \\ Tirando 0 o de sob as asas maternas, o ruidoso
}

e mandou que, de metro de um só pé, crescesse em número

e seguiu de pronto, desde cima, o declive dos pés erradios

tão rápido, nisso, quanto as pernas velozes dos fithotes de gamo

e faz vencer, impetuosos, as colinas no rastro da sua nutriz querida,

até que, de dentro do seu covil, uma fera cruel, ao eco do balido, pule

mãe, e lhes saia célere no encalço pelos montes boscosos recobertos de neve.

Assim também o renomado deus instiga os pés rápidos da canção a ritmos complexos.

do chão de pedra pronta a pegar alguma das crias descuidosas da mosqueada

balindo por montes de rico pasto e grutas de ninfas de fino tornozelo

que imortal desejo impele, precipites, para a ansiada teta da mãe

para bater, atrás deles, a vária e concorde ária das Piérides

até 0 auge de dez pés, respeitando a boa ordem dos ritmos,

arauto dos deuses, Hermes, jogoura à tribo dos mortais,

e pura, ela compôs na dor estrídula do parto.

do rouxinol dórico

benévolo.

"O Ovo", 325 a.C., Símias de Rodes, tradução uıreld uo gregu por José Paulo Paes.

poema metalingüístico, trata do nascimento do poema (ou canto) e da busca de sua perfeição. Nele, o canto é metaforizado pelo ovo do pássaro rouxinol (aedóon em grego, derivado de aeídoo, o verbo cantar, de que também deriva o termo aedo, cantor/poeta).

Após um salto de 1200 anos das tecnofanias de Rodes, a poesia visual voltará a ser feita na forma das carmina figurata na baixa idade média, durante a renascença carolíngia em que os cléri- 
gos buscaram dar à linguagem um caráter revelador, elevando o texto a uma manifestação sagrada.

A carmina figurata ou carmen figuratum apresenta uma estrutura extremamente complexa, realizando um elo entre uma visualidade simbólica e a escrita alfabética latina. Nela, um texto

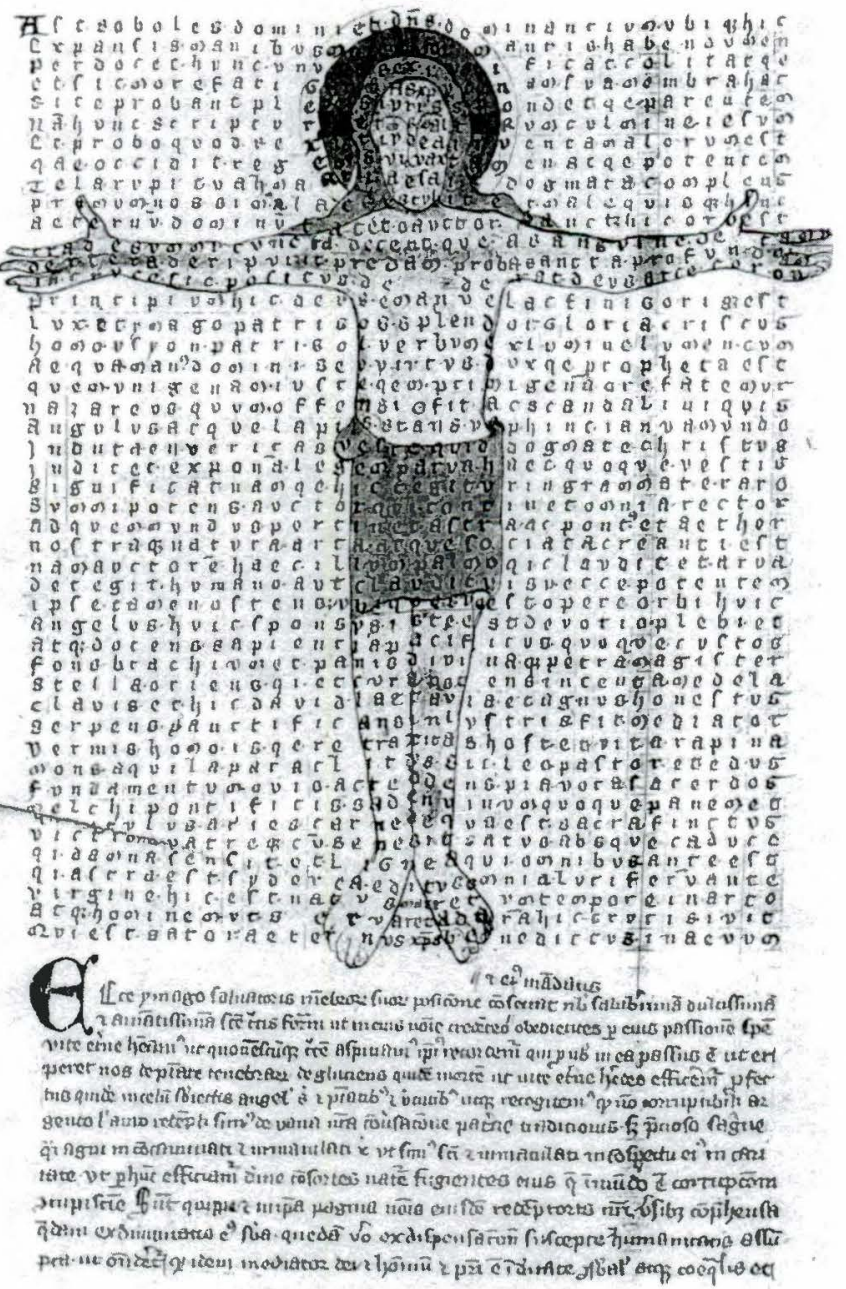

Carmina figurata $n-1$, Rabanus Maurus 
oculto vem formar um desenho de valor esotérico a partir da materialidade de certas letras, dentro de um texto maior. Cria-se, assim, uma revelação metafísica através da relação entre um microtexto escondido, uma figura simbólica desenhada e um macrotex to poético. Segundo o medievalista suíço Paul Zumthor (1975), sob sua pena a carmen figutatum manifesta a unidade conceitual e simbólica da página: os versos iguais em número de letras, são compostos de modo a conter, em lugares determinados, letras tais que formem (extraídas das palavras às quais pertencem e religadas umas as outras) uma frase revelando o sentido oculto do poema.

$\mathrm{O}$ desenho do microtexto, muitas vezes dado normalmente por marcas gráficas, pela coloração ou caractere variante, também poderia vir delineado por traços. Porem, quanto mais sutil essa dife-

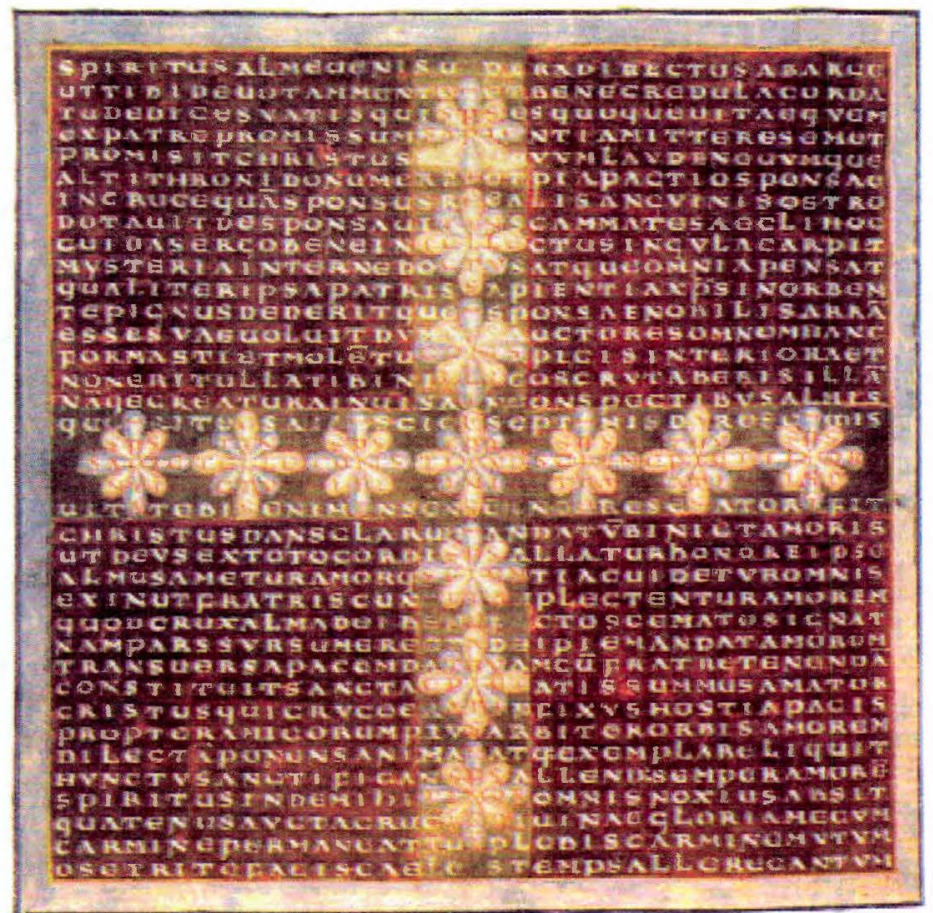

Carmina figurata, Rabanus Maurus 
renciação material, maior o peculiar efeito de destacamento do texto figurado do plano.

A carmina figurata aparece em uma forma muito prematura já no Baixo Império Romano por volta de 350 , quando o poeta e prefeito de Roma Porphyrius Optatianus realiza uma pequena série de poemas, os carmina cancellata, em que versos de mesmo número de letras comportam simples figuras geométricas como a forma de uma cruz. Tais trabalhos, de mero enfoque ornamental, redescobertos pelos letrados carolíngios no século IX, vieram dar origem à complexa forma conceitual das carminas figuratas.

O principal artífice da carmina figurata chama-se Rabanus Maurus. Seu trabalho de fé, embora altamente intelectual, baseia-se num método de interpretação cosmológica da realidade. Procurava

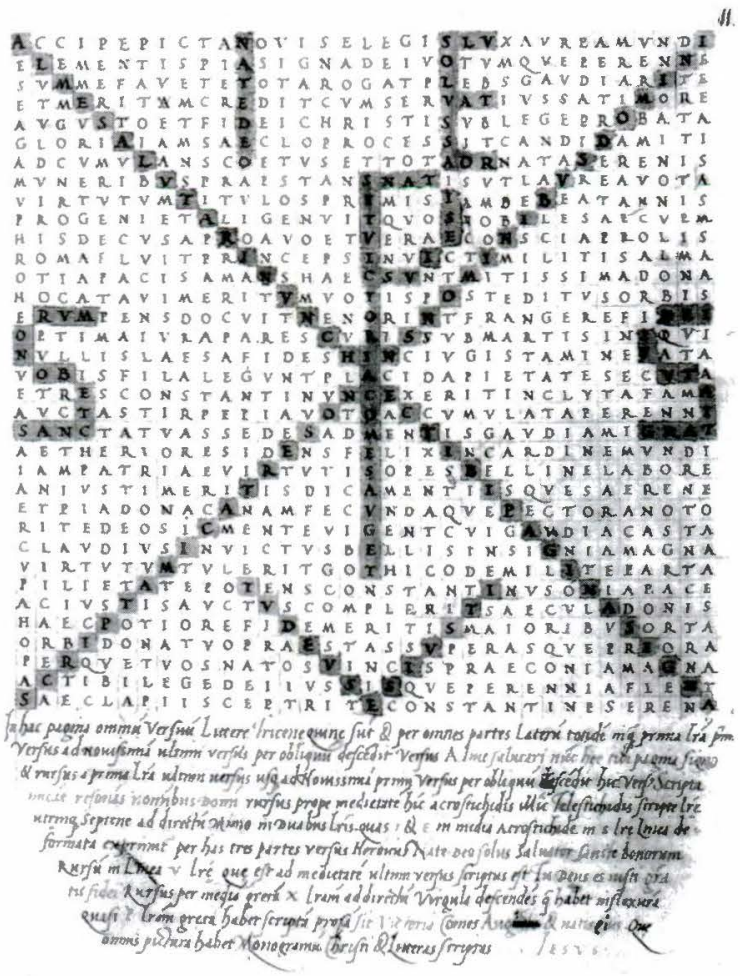

Carmina cancellata, Porphyrius Optatianus 


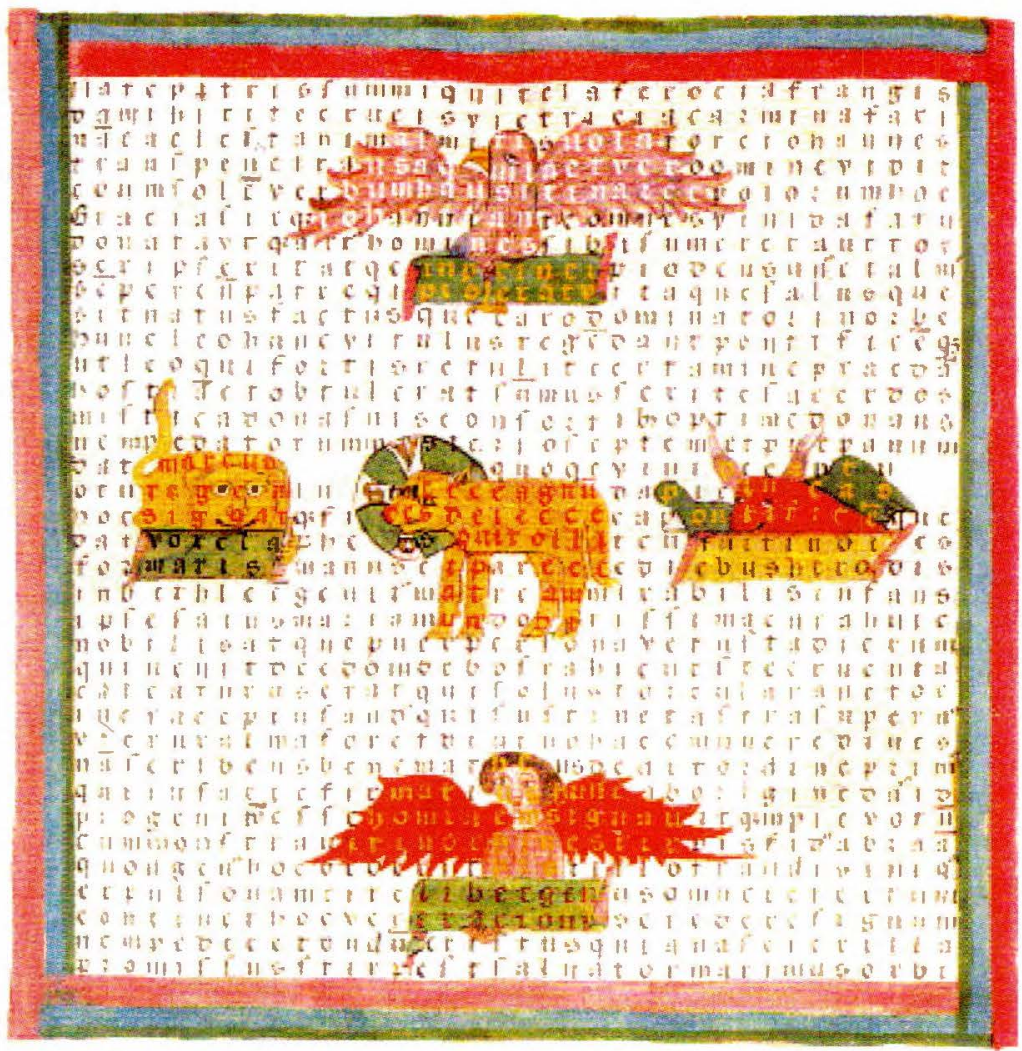

Carmina figurata n-15, Rabanus Maurus

a estrutura metafísica do mundo e dos céus através de complexas fórmulas numéricas aplicadas ao texto, como descreve Paul Zumthor(1975):

O livro comporta vinte e oito poemas: 4 vezes 7 , o número das direções cósmicas multiplicadas pela cifra do sabedoria, segundo uma das proporções que se costuma usar na representação do crucifixo. A cruz é a figura macrocósmica do homem (desenho do poema de dedicatória e dos números 1,4 e 28: 1x4, 4x7); o homem por sua vez reveste quatro figuras: o imperador(dedicatória), o Cristo (n-1), o Anjo (n-4), e o adorador desenhado como o próprio autor (n-28). 
Assim o que a obra cinge não é nada menos do que a totalidade das formas possíveis: das esferas celestes ao monge prosternado, passando por todas as ordens de criaturas (mesmo os animais, no desenho n-15: as bestas do Evangelho em volta do Cordeiro) e, significadas por elas, a partir do centro redentor, as hierarquias do universo invisivel.

O período barroco, de grande complexidade sócio-cultural e de grande efervescência da expressão artística, constitui uma época

\section{XVIII}

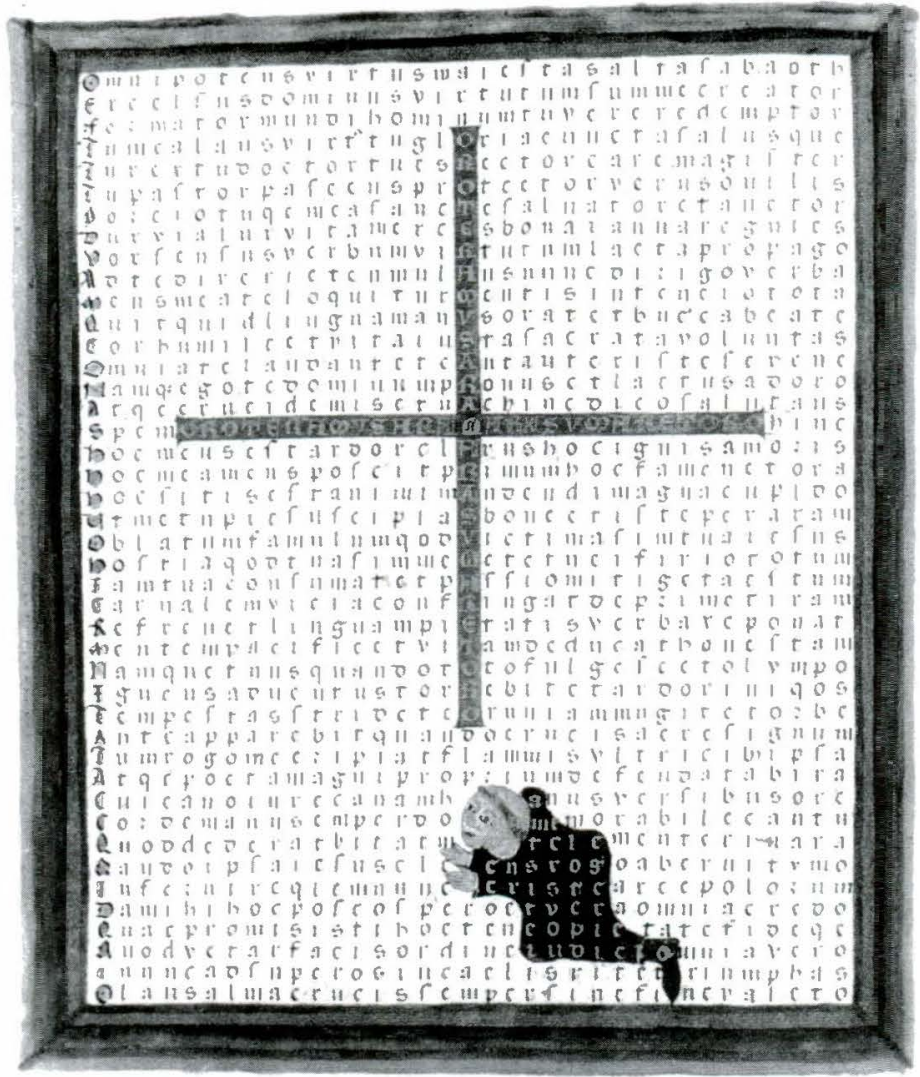

Carmina figurata n-28, Rabanus Maurus 
de contradições, excessos, de reformas e contra-reformas, de obras labirínticas de uma intensificação dos recursos estilísticos e retóricos, e, também, mais um período de criação dos poemas figurativos.

Neste período, a poesia visual volta em numerosa produção cujas principais formas foram: os acrósticos, em que as letras iniciais

REJEIL

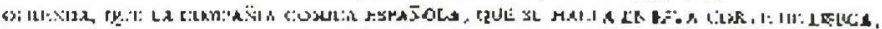

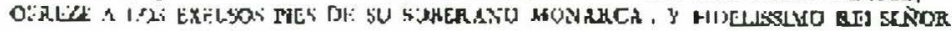

D. $\mathrm{O} O \mathrm{~S}$ E $\mathrm{P}$ H $\mathrm{I}$.

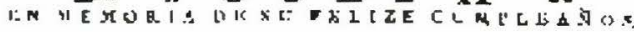

$$
0<T \& \mathbb{R} \text {. }
$$

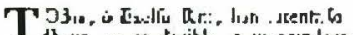

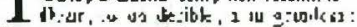

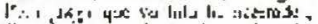

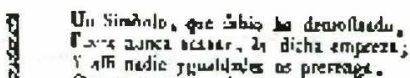
Q. Wh : L

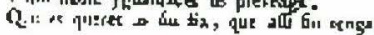

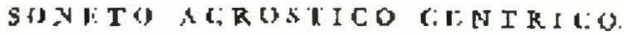

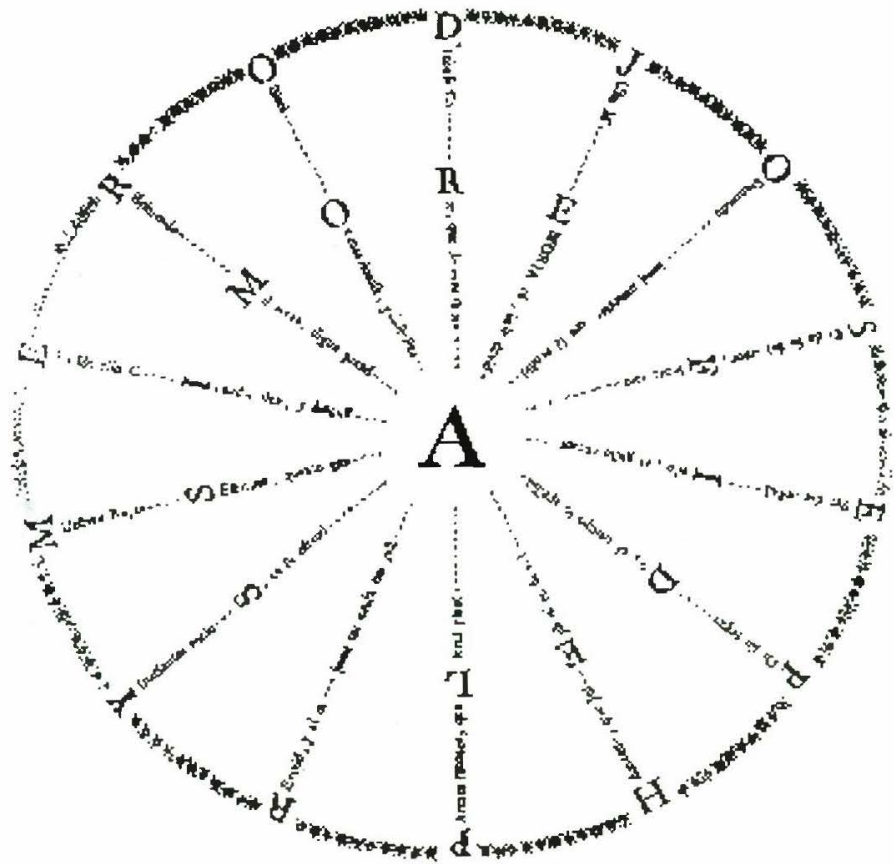

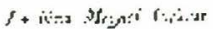

Soneto acróstico, 1734. 
dos versos compõem palavras ou frases; os anagramas, palavra ou frase formada da transposição das mesmas letras de outra palavra ou frase; os labirintos cúbicos, em que o deslocamento espacial de uma letra em inúmeros versos repetidos compõe uma malha visual que contém pequenos textos ocultos.

Destaco apenas exemplos do barroco português devido à maior proximidade com a nossa cultura. Contudo, há exemplos de poemas visuais por toda Europa, principalmente na Alemanha.

O século XX consiste no período da complexidade, dos extremos (ainda maiores que os barrocos), das revoluções e velocidade;

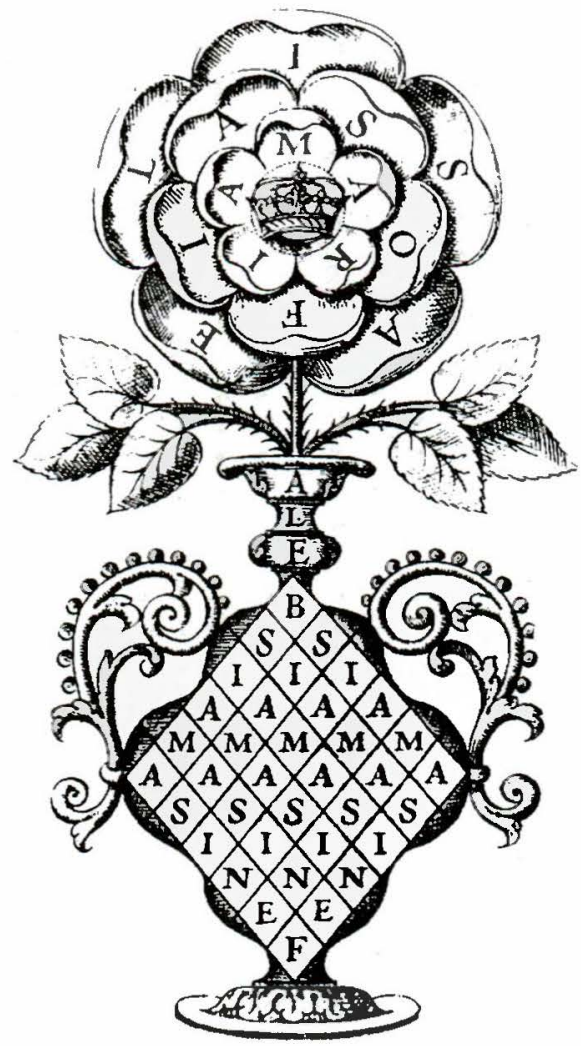

Anagrama poético, séc. XVII, Luís Nunes Tinoco. 


\section{LABYRINTHO DIFFICULTOSO}

Em que, fe expende a materia da Obra.

SoE I O O L

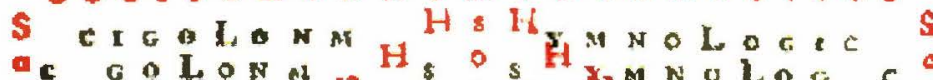
6. G L L O N A H

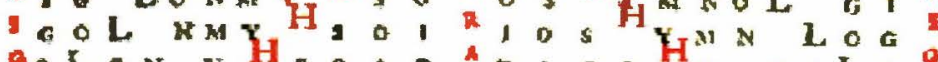

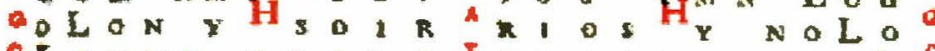

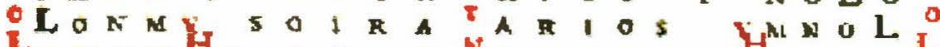

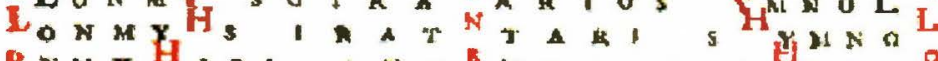

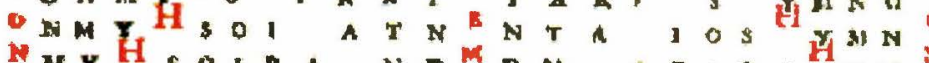

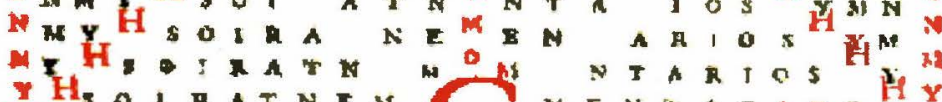

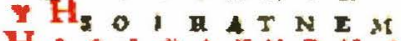

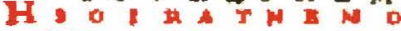

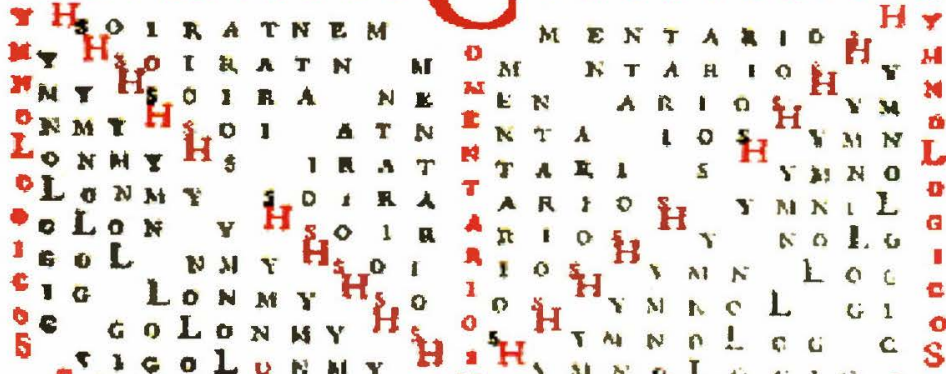

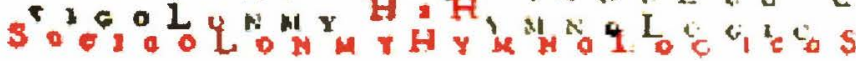

Labirinto Cúbico,1738, José da Assunção.

época da psicanálise, teoria da relatividade, do avanço da linha de montagem fordista, comunismo-capitalismo-facismo, as vanguardas artísticas, a criação da publicidade, o avanço do cinema; e em meio a esse turbilhão histórico ocorre a explosão da poesia visual.

O século XX é o momento histórico em que a visualidade toma uma fundamental importância devido a fatores como o desenvol- 
vimento da indústria gráfica com a melhoria das técnicas de impressão e inclusão de fotos junto aos textos, as produções cinematográficas e a televisão, a criação e o bombardeio da publicidade, o design, o avanço ilimitado dos meios de comunicação.

Pela primeira vez, a poesia figurativa não mais aparecerá como uma criação efêmera e isolada de uns poucos autores. Segundo Philadelpho Meneses (1998):

Ela passa a ser uma forma central da poesia de todas as vanguardas de nosso século. Por isso, a referência à 'poesia visual' reporta a esse conjunto plural de manifestações ligadas à cultura moderna e contemporânea. Se, formalmente, há formas poéticas visuais no passado, quando elas ressurgem com força total, neste século, estão diretamente ligadas a um quadro específico da cultura, com outras intenções e outros significados, que fazem essa poesia visual nitidamente diferenciada da antiga.

A poesia figurativa no século $\mathrm{XX}$ aponta como uma forma radical de experimentação literária. O número de obras figurativas realizadas no período é incalculável; o que fica claro é um processo de reciclagem muito dinâmico em que todos os modos de criação da poesia visual interagem entre si. Para mapear tamanha produção, resolvi criar uma breve antologia histórica da poesia visual moderna e contemporânea.

$\mathrm{Na}$ virada do século, em 1896, o poeta simbolista francês Stéphane Mallarmé criará o emblemático poema "Um Lance de Dados" que servirá como paradigma para toda criação poética visual do século seguinte. O poema de extrema complexidade, trabalha simultaneamente o espaço, a forma, os caracteres, o tempo, a musicalidade, na criação de uma polifonia de sentidos.

As páginas, sempre em dupla, são tratadas como um campo visual ativo, a fragmentação das frases, repletas de elipses, cria uma estrutura nova de discurso, rompendo com a sintaxe verbal: dando sentido não mais às frases, mas sim a conjuntos de palavras distribuídas 
como constelações num céu. O poema, ainda, apresenta a incomparável riqueza hermética e metalingüística do autor.

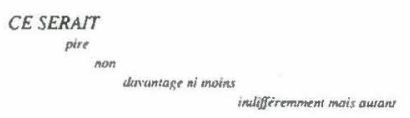

"Um Lance de Dados", duas páginas, 1896, Stéphane Mallarmé.

O futurismo italiano, o primeiro movimento organizado de vanguarda, também será o primeiro movimento de poesia visual. O movimento tem o seu início em 1909 com o lançamento do primeiro manifesto literário pelo poeta mentor do grupo F. T. Marinetti. O futurismo italiano extremamente político e revolucionário, idealizaram suas obras como verdadeiros balés mecânicos, atuando nas diversas áreas artísticas; pregando a destruição da tradição e dos museus, a exaltação da tecnologia, da velocidade e do militarismo.

Através de vários manifestos literários literário escritos por Marinetti, os futuristas gradativamente chegaram à poesia visual: 


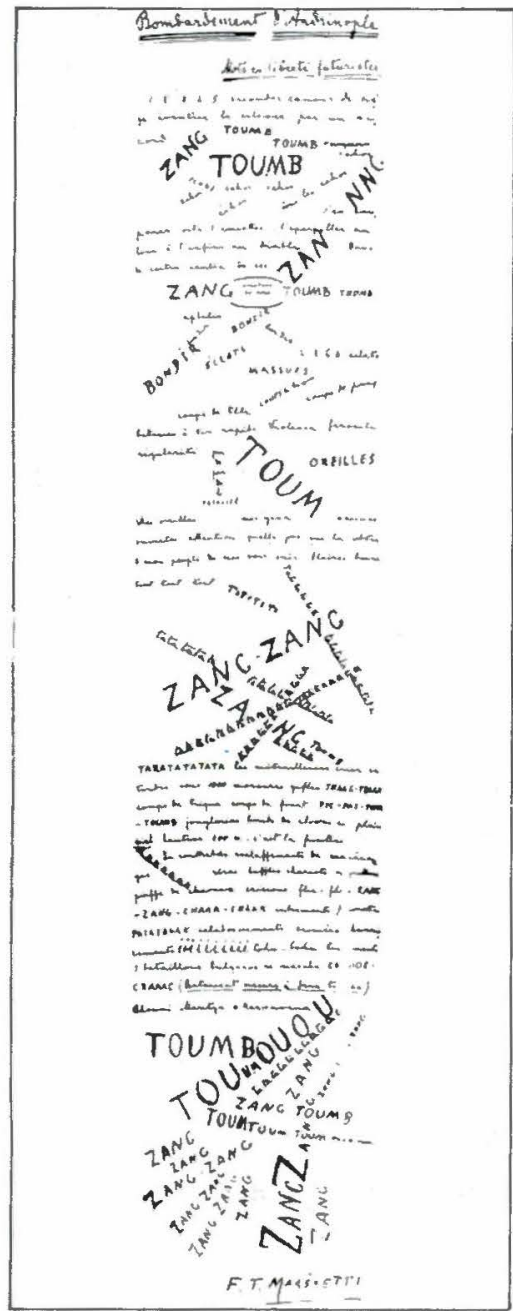

"Zang Tumb Tuum", 1914 , F.T. Marinetti.

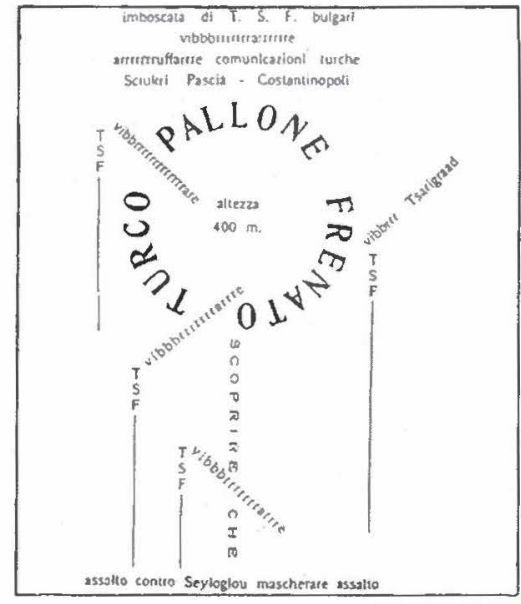

"Bomberdeamento de Aeroplano", 1913, F.T. Marinetti.

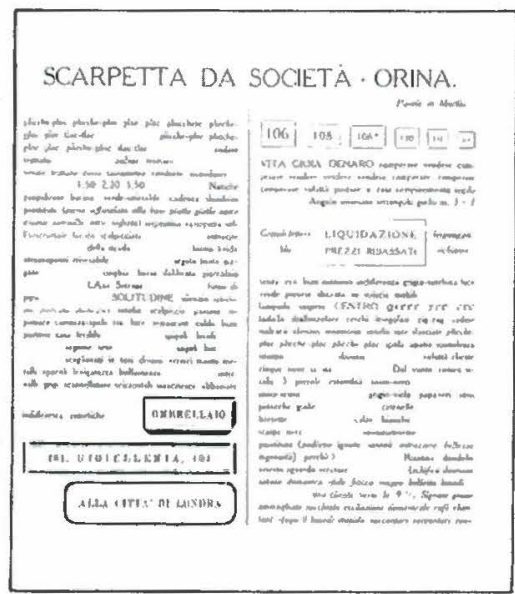

"Scarpetta da società + origina", 1913, Umberto Buoccioni.

primeiro, aboliram as rimas dos versos; segundo, com a Parole in Liberta trabalharam com a livre associação das palavras, criam o verso livre rompendo a estrutura métrica do verso, e, finalmente, 
com as tavole parolibere (quadros de palavras livres) trabalham visualmente o poema com as palavras distribuídas no espaço. Os poemas deveriam ser como o barulho de um motor ou uma rajada de metralhadora e as criações visuais tentavam captar a caótica realidade industrial.

\section{Ritratto di Marinetti}

\section{A Marinetti}

Parole in libertà

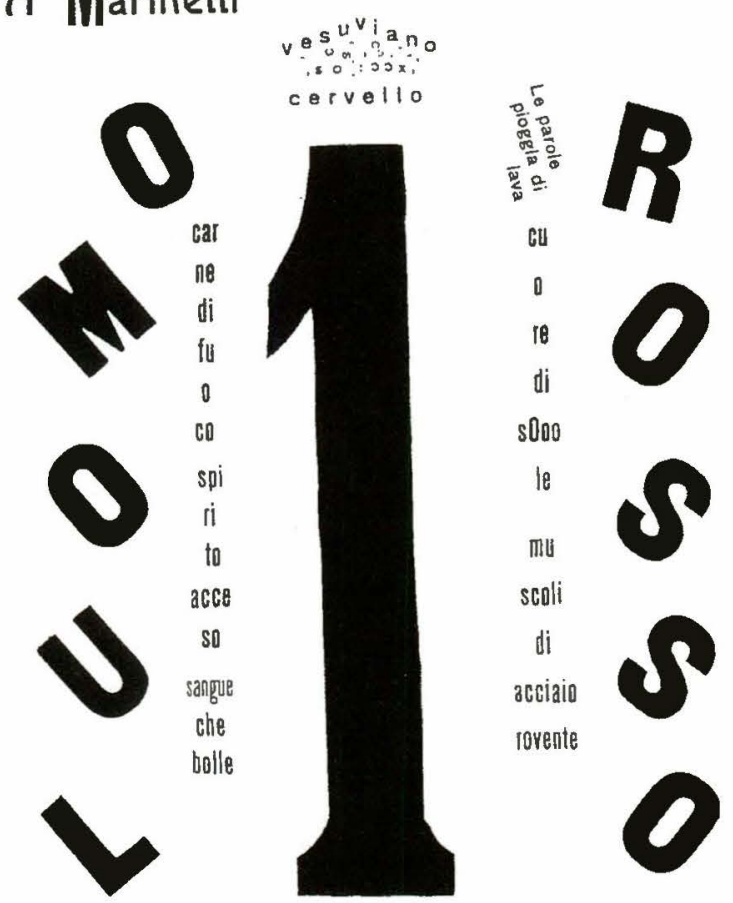

"Retrato de Marinetti", 1916, Marieta Angelini.

A vanguarda russa, do início do século, foi outro grande pólo produtor de poemas figurativos. Produzindo uma arte extraordinariamente racional e a frente de seu tempo, realizaram ao máximo as propostas futuristas. Os vanguardistas romperam as barreiras entre as mídias fazendo uma mistura entre a literatura, a fotografia, a pintura, o cinema e a propaganda. 
Formando um refinado pólo intelectual, onde as artes entrecruzavam-se, e seguindo o lema de Maiakóvski de que não existe uma arte revolucionária sem uma forma revolucionária, vieram mudar o rumo das diversas artes, través de obras como o cinema de Eiseinten, a pintura de Malievich, poesia de Maiakovski etc.

\section{Bb|3OB}

КАК॰Ф"Нію ДУШи

MoTOPOB с $4 * \varnothing 0 * i w$

$\Phi$ P P P P P p P P p

это Я это Я

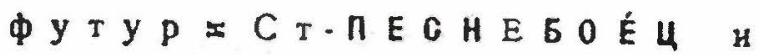
ПиЛОТ-АВІАТО $*$ )

В А С ИЛ, Й НА МЕН СК Й

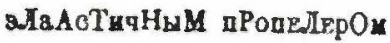

ВВННТИЛ ОБлА гА

киНув Т A $M$

$\therefore$ З В В 3 К Т

ДряБлоЙ смерти КонотКш

из ЖалоСти сшитое

\section{TAmrOBoe MaHtO n}

чУЛКИ $\mathrm{c}$

П А Ш Т А Л О Н $\mathrm{MH}$

"Desafio", 1914,Vassíli Kamiênski. 


\section{DESAFIO}

$\mathrm{CAC}^{\circ} \mathrm{F}^{\circ} \mathrm{Nia}$ da $\mathrm{ALMa}$

sinfonia de MoTOrES

freterter

sou Eu sou Eu

futur-Sta-CANTOLUTADORe

PILOTO-AVIADOr*)

VAS SIL i K A M I EN S K I

cOm hÉlIcE eLaĀsTiCa

APARAFFUSEI AS $\bigwedge$ UVENS

laNçando $\quad \mathrm{L} \AA \AA$

de visita

a Flácida morte COCOT as

bordado de PiedAde

um $\mathrm{M}$ a $\mathrm{N}$ t de TAngOe

MEIAS com

PA I T ALONAS

"Desafio", 1914,Vassíli Kamiênski, Tradução de Augusto de Campos.

A poesia figurativa russa a princípio segue as idéias da tavole parolibere, porém a supera em muito devido a uma forte influência da pintura e da fotomontagem. A linguagem gráfica destes poemas, do início de século, é tão sofisticada que até hoje não foi plenamente superada, suas composições são de um complexo, porém, sintético design equivalentes às pinturas suprematistas de Malievich. 

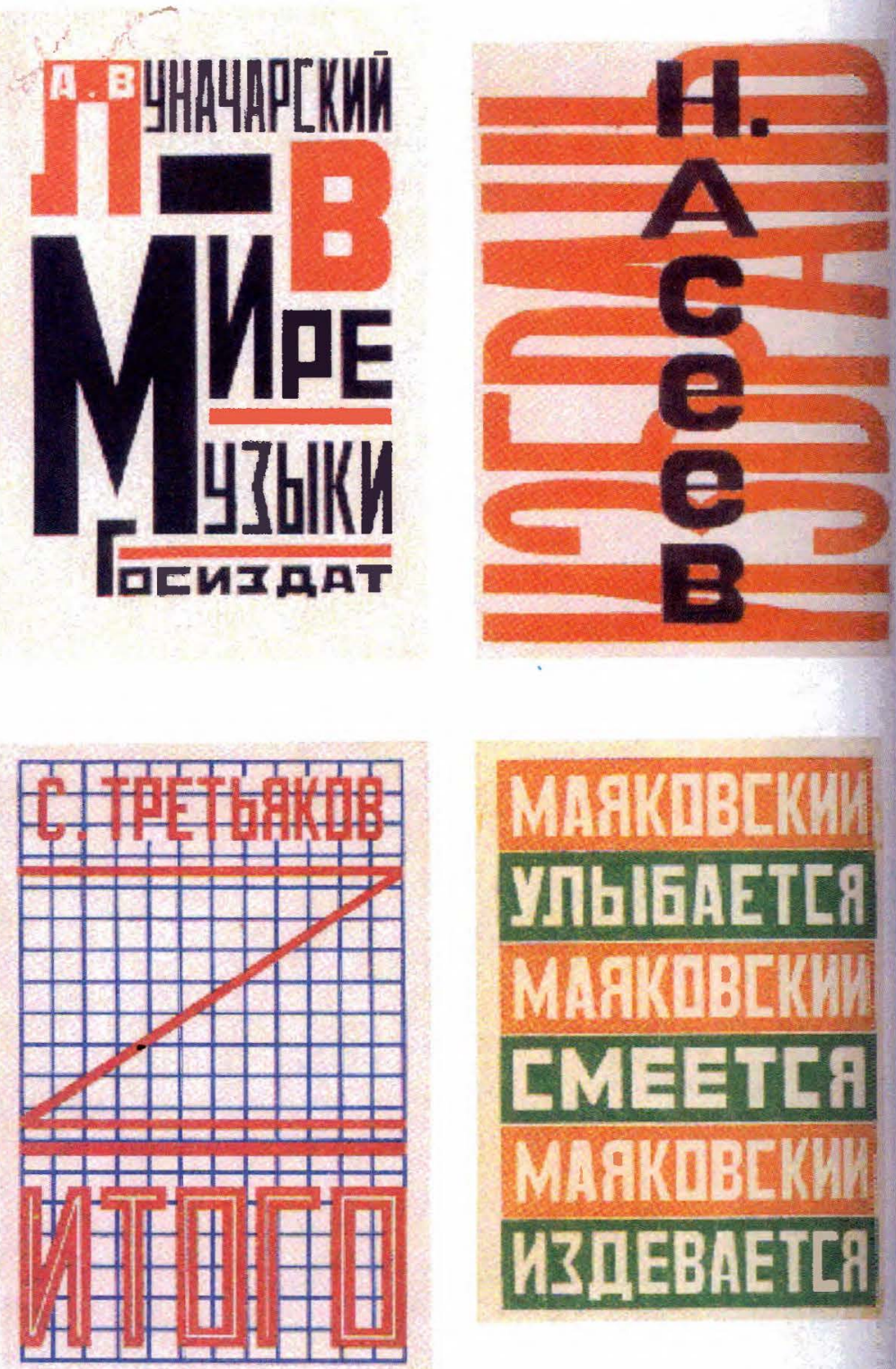

1920, Aleksandr Rodchenko 
Em 1918, o poeta, prosador e crítico francês Guillaume Apollinaire lança o seu livro Caligrammes que viria causar um grande impacto na poesia de vanguarda. O livro apresenta os caligramas, poemas visuais que contém isomorfismos com o conteúdo, ou seja, a forma visual do poema é a mesma do objeto que descreve.

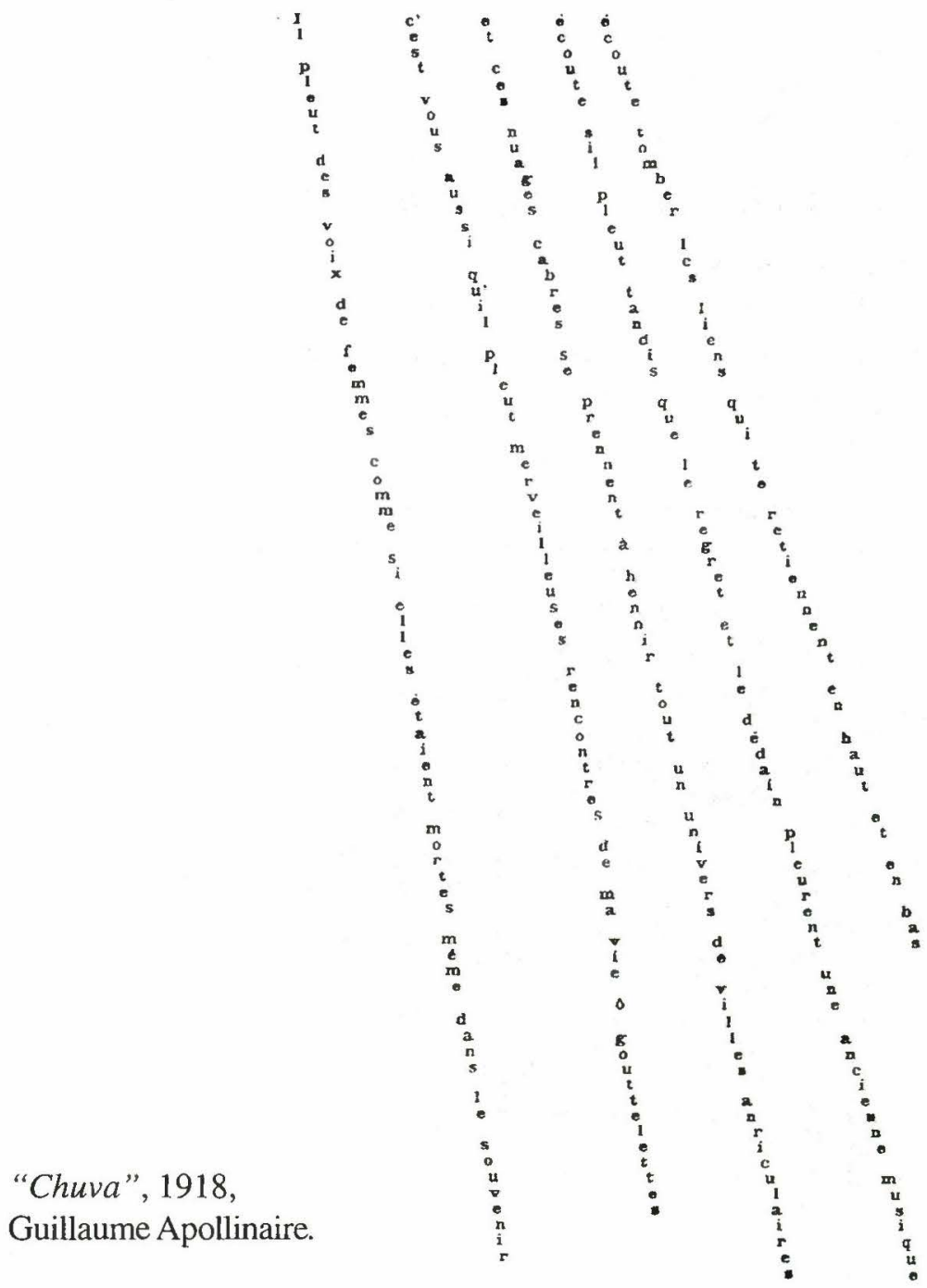


O concretismo criado em São Paulo, em 1958, por Décio Pignatari e pelos irmãos Augusto e Haroldo de Campos e difundido na Europa pelo poeta português E. M. de Melo e Castro e foi o único movimento poético de vanguarda brasileiro a alcançar significativa repercussão internacional.

Fazendo uma síntese da poesia figurativa do século XX somada ao processo de composição do ideograma Chinês, a poesia concreta vem decretar a superação do verso por uma sintaxe espacial e nãoverbal. Sempre excessivamente racionais, os poetas concretos buscaram uma comunicação dinâmica e direta, trabalhando com o espaço gráfico da folha e com uma coisificação/substantivação da linguagem.

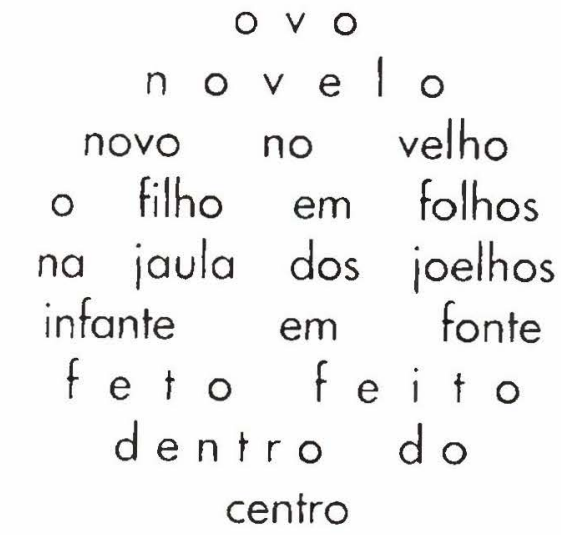

"Ovonovelo", 1956, Augusto de Campos

A poesia figurativa, a partir da década de 60 , através de processo evolutivo de reciclagem de suas diversas formas, chega ao ponto da criação de poemas sem palavras ou letras, (embora, se possa encontrar alguns esparsos exemplos na década anterior). Normalmente, são poemas visuais artesanais de pequena tiragem, feitos em serigrafia, litografia, em colagem, ou até mesmo objetos. São poemas compostos por figuras de linguagem aplicadas a imagens puras. Trabalha-se, assim, as imagens com uma estrutura linguística 
similar ao do poema verbal - como os oximoros visuais do poeta catalão Joan Brossa: um lápis que vaza tinta ou uma roda perfeitamente quadrada.
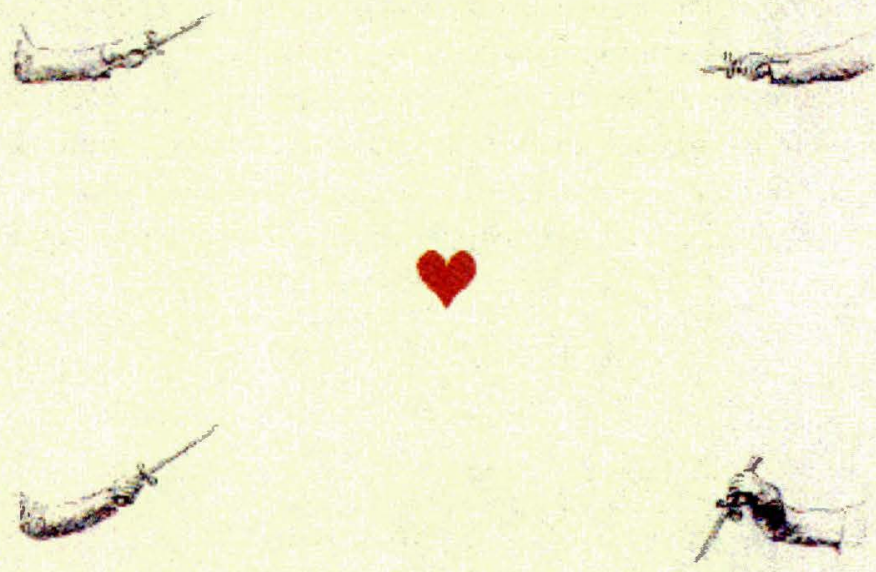

Esgrima, 1982, Joan Brossa.

A partir dos anos 70, a poesia visual, até então expressa basicamente através do meio gráfico (livro, cartaz e gravura), vem buscar novos meios de suporte. Surgem então os primeiros poemas performances.

Segundo o poeta português Fernando Aguiar (1985),

A performance possui uma série de componentes que podem ser explorados esteticamente. Conceitos como o tempo, o espaço, o movimentolação, a tridimensionalidade, a cor, o som, o cheiro, a luz e, principalmente, a presença do poeta como detonador e fator de consecução do poema, (...) conferido-lhe uma outra dimensão e propor- 
cionando ao leitor/fruidor o "poema total", o poema em sua plenitude comunicacional e informacional.

A presença física do operador do poema é o fator principal da performance. $\mathrm{O}$ artista entra como um signo novo, dotando o poema de pulsação-respiração-movimento, trazendo o poema para um novo espaço; o do corpo, do mundo, do sexo e, principalmente, da vida.

Esses poemas, por se darem no tempo real (o mesmo da vivência do espectador), tornam-se efêmeros e não repetíveis, porém o feedback do público é um fator essencial no desenrolar dos poemas. Segundo Fernando Aguiar (1985), a performance poética possibilita o criar-se e o estar ali para ver. Possibilita a informação integrada recíproca e instantânea. Apela à participação.

Hoje, num momento de enorme produção da poesia visual repleta de hibridismos de um pós-tudo - pós: concretos, figurativos, poema-objeto, performances -, resulta-se numa complexa e muitíssima variada produção em que o poeta lança mão de vários recursos das diversas linhas de poesia visual, o que dificulta uma sistematização da poesia visual contemporânea. Porém algumas tendências já apontam para o que será da poesia visual no século XXI, certamente, o uso dos computadores será propulsor de um novo fôlego. A infopoesia expande quase ao infinito as possibilidades do poeta de lidar com espaço, cor, luz, som, movimento e fundamentalmente a interatividade.

A poesia pixel de E. M. de Melo e Castro (2000) é um destes exemplos, realizada através de uma intensa manipulação das imagens pela computação gráfica (abusando das estruturas visuais de fractais). Levanta questões como da relativização da autoria na dinâmica poeta-programa-autor-software, quem fez o quê.

A poesia visual vem ganhar uma extrema potencialidade com os computadores, dando-se essencialmente em três níveis que são combinados livremente na obtenção dos mais inusitados resultados. Primeiro, na sinergia autor-computador, como visto no caso de Melo e Castro (2000). Segundo, na relação leitor-poema, em poemas criados no formato de hipertextos, em que o leitor possui um texto ligado simultaneamente a uma série de outros textos (escritos, visuais, so- 
noros etc) formando uma rede de links em que o leitor virá navegar. Terceiro, na relação autor-autor, na facilidade de criação conjunta de poemas via Internet, um espaço virtual em que o poema sempre se encontrará aberto a modificações.

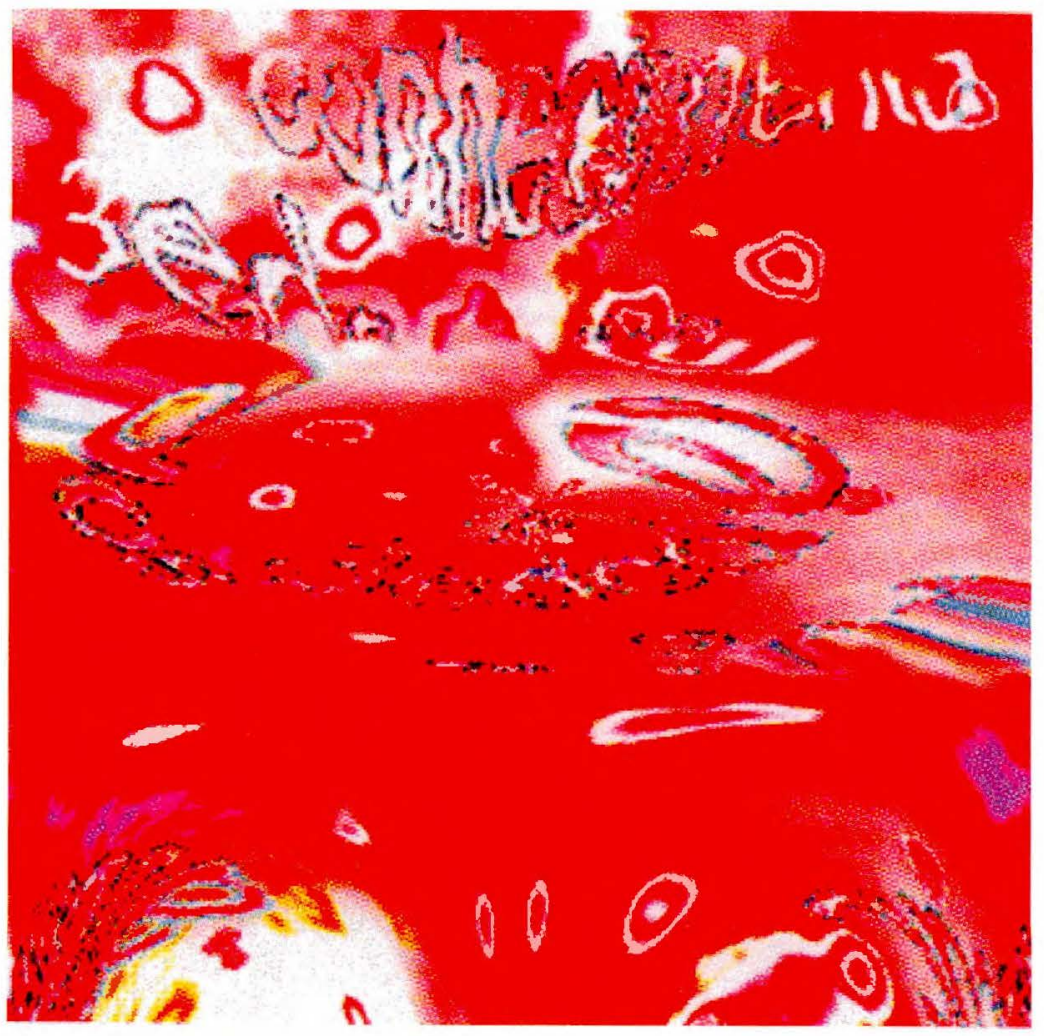

2000, E. M. de Melo e Castro. 


\section{Bibliografia}

AGUIAR, Fernando. 1985. Poesia ou a Intervenção Viva. Reeditado in: MENEZES, Philadelpho(Org). 1998. Poesia Sonora. São Paulo: Educ, pp. 145150.

ARGAN, Giulio Carlos. 1996. Arte Moderna. São Paulo: Cia. das Letras.

CAMPOS, Augusto e Haroldo de; PIGNATARI, Décio. 1991. Mallarmé. São Paulo: Perspectiva.

CAMPOS, Augusto e Haroldo de; SCHNAIDERMAN, Boris. 1987. Poesia Russa Moderna. São Paulo: Brasiliense.

CAMPOS, Haroldo de (org.).1994. Ideograma: Lógica, Poesia, Linguagem. São Paulo: Edusp.

CASTRO, E. M. de Melo e. 2000. Antologia efêmera. São Paulo: Lacerda.

1993. O fim visual do século XX. São Paulo: Edusp. II.

1998. Vôos da Fênix Crítica. Lisboa: Edições Cosmos, vol.

CENTRO DE ESTUDOS PORTUGUESES. 1998. Revista do Centro de Estudos Portugueses. São Paulo: USP, n. 1.

COOK, Geoffery. Citação in CASTRO, E.M. de Melo e. Uma Rede Intersemiótica, 1993. O fim do século XX. São Paulo: Edusp, pp.217.

DURAND, Gilbert. Le Labyrinthe. Paris: Fondation Calouste Gulbenkian.

DABROWSKI, Magdalena. 1999. Aleksandr Rodchenko. Nova Iorque: Moma.

ERNEST, Von Ulrich.1991. Carmen Figuratum. Alemanha: Editora Böhlau.

IVAM, Institut Valencià d'Art Modern. 1997. Poesía visual - Joan Brossa. Valência: IVAM.

MENEZES, Philadelpho(Org).1998. Poesia Sonora. São Paulo: Educ.

MENEZES, Philadelpho.1998. Roteiro de Leitura: Poesia Concreta e Visual. São Paulo: Ática. 
NICOLETTA, Misler.1998 Art Dossier Avanquardie Russe. Itália: Giunti.

PAES, José Paulo.1995. Poemas da antologia grega ou platina. São Paulo: Cia.das Letras.

PIGNOTTI, Lamberto. 1987. Figure scritture. Roma: Campanotto Editore.

ZUMTHOR, Paul. 1990. Poesia do Espaço. Reeditado em MENEZES, Philadelpho(Org).1998. Poesia Sonora. São Paulo: Educ, pp.138-144.

1975. Carmina Figurata. Reeditado em 1994. Revista USP, dossiê Palavra Imagem. São Paulo: USP, n. 16, pp. 69-75. 